\title{
Interação total entre o campus Assis Chateaubriand - Instituto Federal de Educação do Paraná e a comunidade externa
}

\author{
Ana Lúcia da Silva Lima , Fábio Zanella², Gabriela Martins Gimenes³, Camila Maria da Silva Pin³, Sara \\ Bianca Rodrigues Albuquerque3, Jessica Aparecida de Souza Nascimento33, Debora Juliete Pereira \\ Correia Santos 3
}

\begin{abstract}
Resumo: Para o desenvolvimento educacional e social, as parcerias entre entidades públicas e privadas são essenciais e desejáveis, sempre contemplando a valorização de um bem maior, o ser humano. No âmbito educacional, a troca de experiências e de saberes consolida o tripé ensino, pesquisa e extensão. Desta forma, a oferta de ações de interação entre a comunidade interna do campus Assis Chateaubriand do Instituto Federal de Educação do Paraná (IFPR) e a comunidade externa está claramente institucionalizada em Programas e Projetos de Extensão do IFPR. O presente projeto objetivou sistematizar formalmente ações de extensão e educacionais comunitárias que causaram impactos positivos em diferentes segmentos da sociedade local. Durante o período de junho a outubro de 2019, foram desenvolvidas ações comunitárias, como por exemplo, oficinas, encontros, eventos e apresentações culturais (teatro). Todas as ações ocorreram de forma satisfatória quanto ao atendimento das expectativas da comunidade participante. Assim, a escola promoveu a construção de valores morais, a formação de cidadãos conscientes e críticos, de pessoas que saibam participar da vida comunitária e que dão valor ao bem-estar pessoal e coletivo, atuando na construção de um mundo melhor.
\end{abstract}

Palavras-chave: Geração de Renda; Interdisciplinaridade; Vulnerabilidade Social

\section{Total interaction between Federal Institute of Paraná and external community}

Abstract: For educational and social development, partnerships between public and private entities are essential and desirable, always in order to contemplate the appreciation of a greater good, the human being. The exchange of experience and knowledge consolidates the tripod teaching, research, and extension in the educational scope. Thus, the offer of interactions between the internal community of the Assis Chateaubriand campus of the Federal Institute of Paraná Education (IFPR) and the external community is clearly institutionalized in Extension Programs and Projects at IFPR. This project aimed to formalize both relevant extensional and educational actions, distributed in all social segments, that positively impacted society. From June to October 2019, community actions were developed, such as workshops, meetings, events, and cultural presentations (theater performances). All the actions took place in a satisfactory way regarding meeting the expectations of the participating communities. Consequently, the school has promoted the construction of moral values, forming conscious and critical citizens: people who know how to be engaged in community life and who value personal and collective well-being, who work to build a better world.

Keywords: Income generation; Interdisciplinarity; Social vulnerability
Originais recebidos em

17 de abril de 2020

Aceito para publicação em

10 de março de 2021

1

Docente do Instituto Federal do Paraná - IFPR (Campus Assis Chateaubriand).

ana.lima@ifpr.edu.br

(autora para correspondência)

2 Docente do Instituto Federal do Paraná - IFPR (Campus Assis Chateaubriand).

3

Estudante do curso de Licenciatura em Ciências Biológicas, Instituto Federal do Paraná - IFPR (campus Assis Chateaubriand). 


\section{Introdução}

O ser humano é naturalmente gregário, desta forma a interação de ideias, costumes, crenças, comportamentos, atitudes, conhecimentos, experiências e valores necessitam ser compartilhados. No mundo educacional, essa troca de experiências e de saberes visa consolidar a indissociabilidade entre ensino, pesquisa e extensão. Assim, ao empreender ações de extensão junto à comunidade local, estreitam-se os laços e disseminam-se os conhecimentos, criando espaços democráticos (Zucco et al., 2019). Uma das mais poderosas armas para a transformação social é a educação, e diversas atividades podem oportunizar mudanças de paradigmas. Assim, as atividades podem ser desenvolvidas em espaços coletivos oportunizando as especificidades de cada comunidade, nos quais se observa a singularidade de cada elemento do grupo e sua interação dinâmica com o coletivo (Velloso, 2005).

Para que tais transformações ocorram, as parcerias entre entidades públicas e privadas são imprescindíveis, na busca de valorização de um bem maior, o ser humano. Desta forma, a oferta de ações de interação entre a comunidade interna do campus Assis Chateaubriand, do Instituto Federal de Educação, Ciência e Tecnologia do Paraná (IFPR) - servidores, estudantes e terceirizados - e a comunidade externa é uma necessidade, e está claramente institucionalizada em Programas e projetos de Extensão. A busca constante do estreitamento entre os laços com a comunidade preserva a Missão, Visão e os Valores do IFPR.

Várias entidades sociais, governamentais, municipais e privadas estão localizadas no município de Assis Chateaubriand e nos municípios da Mesorregião Oeste, sendo assim, o desenvolvimento de ações que busquem estreitar laços e que levem à transmissão e troca de conhecimentos e experiências é relevante. As instituições de ensino, juntamente com a família, têm a responsabilidade de promover a construção de valores morais em pessoas que saibam participar da vida comunitária e que valorizam o bem-estar pessoal e coletivo (Nonaka, 2017).

O presente trabalho objetivou sistematizar formalmente ações de extensão educacionais e comunitárias importantes, e que causaram impactos positivos em diferentes segmentos sociais da sociedade local e regional.

\section{Procedimentos metodológicos}

A equipe responsável pelo desenvolvimento do trabalho de extensão foi constituída por cinco estudantes voluntárias e dois docentes do curso de Licenciatura em Ciências Biológicas, do campus Assis Chateaubriand do IFPR. O campus Assis Chateaubriand do IFPR encontra-se sediado no oeste do Paraná, na cidade de Assis Chateaubriand. O município se estende por $969,6 \mathrm{~km}^{2}$ e contava com 33.028 habitantes no último censo.

As estudantes voluntárias do projeto de extensão tiveram a liberdade para planejar, sistematizar e aplicar diversas atividades desenvolvidas. Além das estudantes que integraram a equipe executora, o presente trabalho contou com outros acadêmicos do curso que atuaram como protagonistas. As ações foram desenvolvidas no período de junho a outubro de 2019, e consistiram em:

1 - Oficina sobre cultivo de plantas medicinais e confecção de mini travesseiros aromáticos e medicinais: a parte teórica do curso versou sobre o cultivo, cuidados, espécies medicinais e a importância das plantas. A parte prática foi desenvolvida com a confecção dos travesseiros, com orientação para o preparo do forro de enchimento, a capa para o travesseiro e o saquinho para adicionar as ervas secas. Os seguintes materiais foram utilizados: ervas de alecrim e camomila; essência de alecrim; cola de tecido ou máquina de costura; fibra para enchimento; lápis ou marcador de tecido; régua; retalho de tecido $100 \%$ algodão para a capa do travesseiro; tesoura e TNT. A cola de tecido foi indicada e utilizada porque boa parte dos participantes não possuía 
máquina de costura. Nesta ação, a parte prática foi desenvolvida pelas estudantes voluntárias juntamente com os docentes.

2 - Apresentações de teatro intitulado "O chá da vovó", com falas sobre as plantas medicinais: o desenvolvimento do teatro seguiu metodologia tradicional para apresentação da peça teatral, com a seguinte sistematização: a) seleção das estudantes voluntárias para atuarem na peça como atrizes; b) foi analisada a história com base no público-alvo; c) analisou-se o palco; d) elaborou-se o texto tentando encontrar as vozes para os personagens; e) foi realizada a revisão do texto; f) todo o enredo foi dividido em cenas e atos; g) cada diálogo foi marcado para cada personagem; e h) realização dos ensaios. A criação e a apresentação da peça teatral foram realizadas pelas acadêmicas voluntárias.

3 - Trabalho de divulgação do processo seletivo do IFPR no comércio local de Assis Chateaubriand: foram realizadas conversas e entregas de panfletos à população. A presente ação não foi elaborada pela equipe do projeto, a qual participou apenas como agente transmissor da informação, atendendo a uma demanda interna da instituição.

4 - Contação de histórias: a sistematização para a realização contou com as seguintes etapas: a) realização de reuniões para definir as histórias e os livros utilizados durante a narração; b) ensaios para treinar a linguagem corporal e a diç̧ão; e c) criação de cenários. Essa atividade, que integra outro projeto do campus, traz o envolvimento das estudantes do curso de Licenciatura em Ciências Biológicas como contadoras das histórias.

5 - Apresentação sobre o tema "Conhecendo as briófitas": as apresentações para os participantes dos cursos integrados sobre os assuntos relacionados ao conhecimento das briófitas foram ministradas por meio de exposição teórica e exposição prático-demonstrativa pelas acadêmicas envolvidas diretamente com o projeto, e também por outros estudantes do curso de Licenciatura em Ciências Biológicas. Durante a apresentação, a explanação versou sobre as estruturas das briófitas (aspectos anatômicos, morfológicos e fisiológicos), método de coleta, e importância ecológica e econômica.

6 - Minicursos ofertados para acadêmicos do curso de Licenciatura em Ciências Biológicas durante a V Semana de Biologia do campus Assis Chateaubriand: Minicurso 1 - Confecção de lâminas anatômicas não permanentes de raiz, caule e folhas - método de confecção de lâminas não permanentes. Metodologia resumida: alguns mililitros de água e alguns mililitros de corante foram aplicados em duas placas de Petri distintas. Utilizando uma lâmina de barbear (ou bisturi) foram realizados cortes transversais bem finos nas partes do vegetal, caule, raiz e folhas. Esses cortes foram colocados em placa de Petri contendo o corante, permanecendo, geralmente, três ou quatro minutos (até corar moderadamente). Após este tempo, os cortes foram retirados do corante e lavados na placa de Petri contendo água. Sobre uma lâmina de microscopia previamente limpa, colocou-se uma gota d'água e, a seguir, com cuidado, um corte de material vegetal, com o auxílio de um estilete. Cobriuse, também com muito cuidado, com a lamínula. Observou-se o preparado ao microscópio. Minicurso 2 Cultivo de plantas medicinais e confecção de mini travesseiro aromático e medicinal, elaborado conforme descrição supracitada. Minicurso. 3 - "Conhecendo as briófitas". Esses minicursos foram ministrados por alunas e docentes do projeto e contou também com estudantes curso Licenciatura.

7 - Participação em oficina sobre recuperação de nascentes em propriedade rural: a recuperação de nascente foi realizada em uma propriedade particular em Terra Nova do Piquiri, por intermédio da Secretaria de Agricultura e Meio Ambiente, com apoio de sua equipe técnica e profissional especialista na recuperação de nascentes, agricultores e os estudantes. Na ocasião, os participantes inscritos puderam aprender sobre a importância da preservação da água, com a recuperação de fontes assoreadas. Para a realização da recuperação das nascentes foi preparado o solo cimento, com a utilização de um saco de cimento para cada nascente, e aproximadamente $1 / 2$ metro cúbico de terra vermelha; foram utilizadas rochas presentes na 
propriedade, água da própria nascente, e algumas ferramentas como enxada, enxadão, carrinho de mão, pá, facão, foice, cano de PVC de 75 e $50 \mathrm{~mm}$.

8 - Eventos: a) evento destinado às mães de alunos em risco de vulnerabilidade social, no qual foram desenvolvidas várias atividades, como artesanato - montagem de telas utilizando o tecido "chitão de algodão", cola de tecido e enfeites (pérolas, brilhos, entre outros); b) "O cientista maluco", sendo uma das experiências realizadas a montagem de um vulcão em erupção que utilizou corante de alimentos, vinagre, detergente líquido e bicarbonato de sódio; e c) evento intitulado "Tarde interativa", organizado pelas acadêmicas do projeto, que realizaram pinturas faciais artísticas sobre o tema natureza em crianças.

\section{Resultados}

O presente trabalho sistematizou formalmente ações de extensão e educacionais comunitárias importantes e que causaram impactos positivos em diferentes segmentos sociais. Participaram das ações de extensão um público de aproximadamente 720 pessoas. Assim, os resultados adquiridos se consolidaram por meio do estreitamento de laços entre a comunidade interna do campus Assis Chateaubriand do IFPR e a comunidade externa.

A oficina sobre cultivo de plantas medicinais e confecção de mini travesseiros aromáticos e medicinais ocorreu nas cidades de Assis Chateaubriand - PR e Iracema do Oeste - PR, e foi criada mediante demanda externa, como parte integrante do programa Encontros e Caminhos, promovido pela ITAIPU BINACIONAL e Prefeitura de Assis Chateaubriand. Essa oficina teve como público-alvo mulheres em risco de vulnerabilidade social, com um total de vinte participantes, e ocorreu no dia 14/06/2019 (sexta-feira), no período da manhã e da tarde, no laboratório de Química do campus Assis Chateaubriand do IFPR (Figura 1A). Na cidade de Iracema do Oeste PR ocorreu no dia 28/06/2019 (sexta-feira), no período vespertino no Centro Comunitário de Iracema, e contou com 22 mulheres participantes. A gratidão exteriorizada pelas mulheres foi algo intenso durante a oficina, 0 que demonstrou que há carência desse tipo de atividade nas comunidades atendidas.

As apresentações do teatro intitulado "O chá da vovó", com falas sobre as plantas medicinais, envolvendo estudantes de educação básica de escolas Municipais e Estaduais de Assis Chateaubriand (Figura 1B) e da região, além de alunos da APAE, sendo demanda interna, ou seja, do campus. A primeira apresentação ocorreu no dia 19/06/2019 (quarta-feira), no período da manhã, com a participação de 30 crianças. A segunda apresentação aconteceu durante a "Mostra de curso" no dia 02/08/2019 (sexta-feira), nos períodos da manhã, tarde e noite, com aproximadamente 150 pessoas.

O trabalho de divulgação do processo seletivo IFPR na cidade de Assis Chateaubriand teve como público-alvo a população do município e o local de ocorrência foi o comércio, no dia 28/07/2019 (sábado), no período da manhã. Durante essa ação foi esclarecido que o Instituto Federal é uma instituição de educação pública e gratuita, visto que algumas pessoas acreditam que há custos para se estudar no IFPR.

A contação de histórias foi realizada durante a "Mostra de curso" e teve como público crianças das escolas municipais e estaduais (Figura 1C), tendo acontecido no dia 02/08/2019 (sexta-feira), no período da manhã, tarde e noite, na biblioteca do campus Assis Chateaubriand do IFPR, com 80 crianças. $O$ trabalho com crianças é muito proveitoso, porque elas têm uma imaginação muito fértil.

A apresentação sobre o tema "Conhecendo as briófitas" para alunos dos Cursos Técnicos Integrados de Agricultura e Agropecuária ocorreu em sala de aula e no laboratório de Biologia do campus Assis Chateaubriand do IFPR, nos dias 05 e 06/08/2019, nos períodos da manhã e tarde, obtendo a participação de 50 estudantes. 

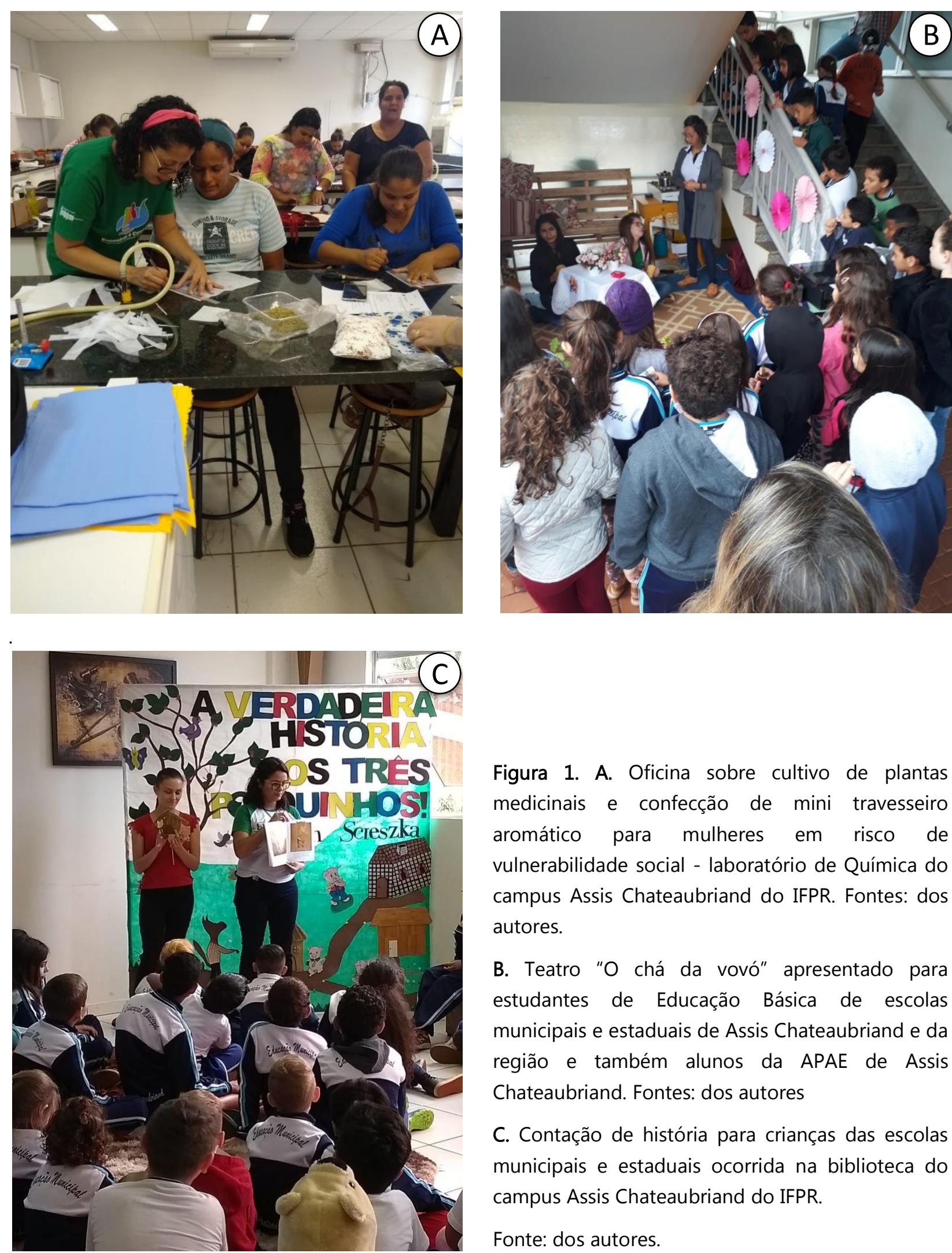

Figura 1. A. Oficina sobre cultivo de plantas medicinais e confecção de mini travesseiro aromático para mulheres em risco de vulnerabilidade social - laboratório de Química do campus Assis Chateaubriand do IFPR. Fontes: dos autores.

B. Teatro "O chá da vovó" apresentado para estudantes de Educação Básica de escolas municipais e estaduais de Assis Chateaubriand e da região e também alunos da APAE de Assis Chateaubriand. Fontes: dos autores

C. Contação de história para crianças das escolas municipais e estaduais ocorrida na biblioteca do campus Assis Chateaubriand do IFPR.

Fonte: dos autores. 


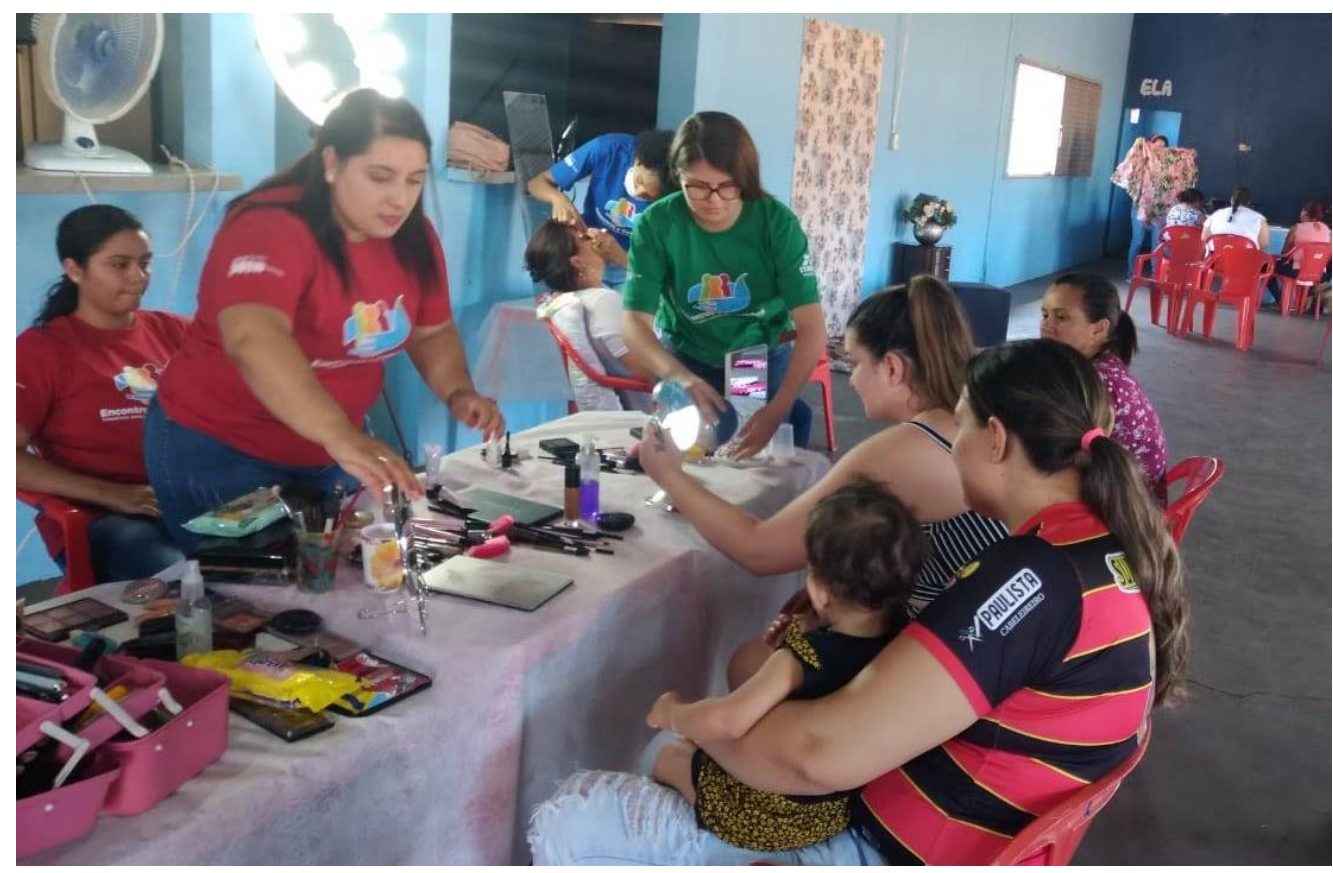

Figura 2. Evento destinado às mães de alunos em risco de vulnerabilidade social, oficina de automaquiagem, da escola "CEMEI criança esperança" em Assis Chateaubriand. Fontes: dos autores.

Foram ofertados três minicursos para acadêmicos do curso de Licenciatura em Ciências Biológicas, durante a V Semana de Biologia do campus Assis Chateaubriand. Foram realizados na data de 08/08/2019, no período noturno e utilizaram os laboratórios de Biologia, Química e Física. Minicurso 1 - Confecção de lâminas anatômicas não permanentes de raiz, caule e folhas; Minicurso 2 - Cultivo de plantas medicinais e confecção de mini travesseiro aromático e medicinal; e Minicurso 3 - "Conhecendo as briófitas". Os três minicursos somaram um total de 43 participantes.

Participação em oficina sobre recuperação de nascentes em uma propriedade na comunidade Terra Nova do Piquiri, atendendo a uma demanda externa do Programa Encontros e Caminhos. O Público incluiu estudantes do curso de Licenciatura em Ciências Biológicas do campus, e o local de ocorrência foi na comunidade Terra Nova do Piquiri, na cidade de Assis Chateaubriand, no dia 23/09/2019, no período matutino e vespertino, com 20 alunos.

Três eventos foram realizados: a - Evento destinado às mães de alunos em risco de vulnerabilidade social, da escola "CEMEI criança esperança" em Assis Chateaubriand (Figura 2), contemplando conversas com a psicóloga, oficinas de telas, curso de automaquiagem, corte de cabelo e design de sobrancelhas: o evento ocorreu para valorização da mulher, e foi realizado no salão Comunitário no bairro Alvorada, no dia 27/09/2019, no período da tarde, e contou com a participação de 20 mães. Os eventos b e c ocorreram durante a ExpoAssis/2019, local no Centro de Exposições de Assis Chateaubriand, entre os dias 19 e 20/10/2019, cujo público participante foi a população de Assis Chateaubriand e região, no período da tarde. $O$ evento b, intitulado "O cientista maluco" foi constituído por diversas experiências na área de Biologia e Química (Figura 3), com a finalidade aguçar a curiosidade dos visitantes por meio de experiências simples. O evento c, "Tarde interativa", foi constituído por diversas atividades para as crianças, como por exemplo, pintura no cabelo, desenhos artísticos no rosto, entre outros. Estes últimos eventos foram desenvolvidos no espaço cedido ao campus durante a exposição municipal, e contaram com a participação de aproximadamente 300 pessoas.

Em todas as ações foi possível observar, por parte de todos os envolvidos, o engajamento, o comprometimento, a valorização, a humanização e a troca de saberes e experiências. 


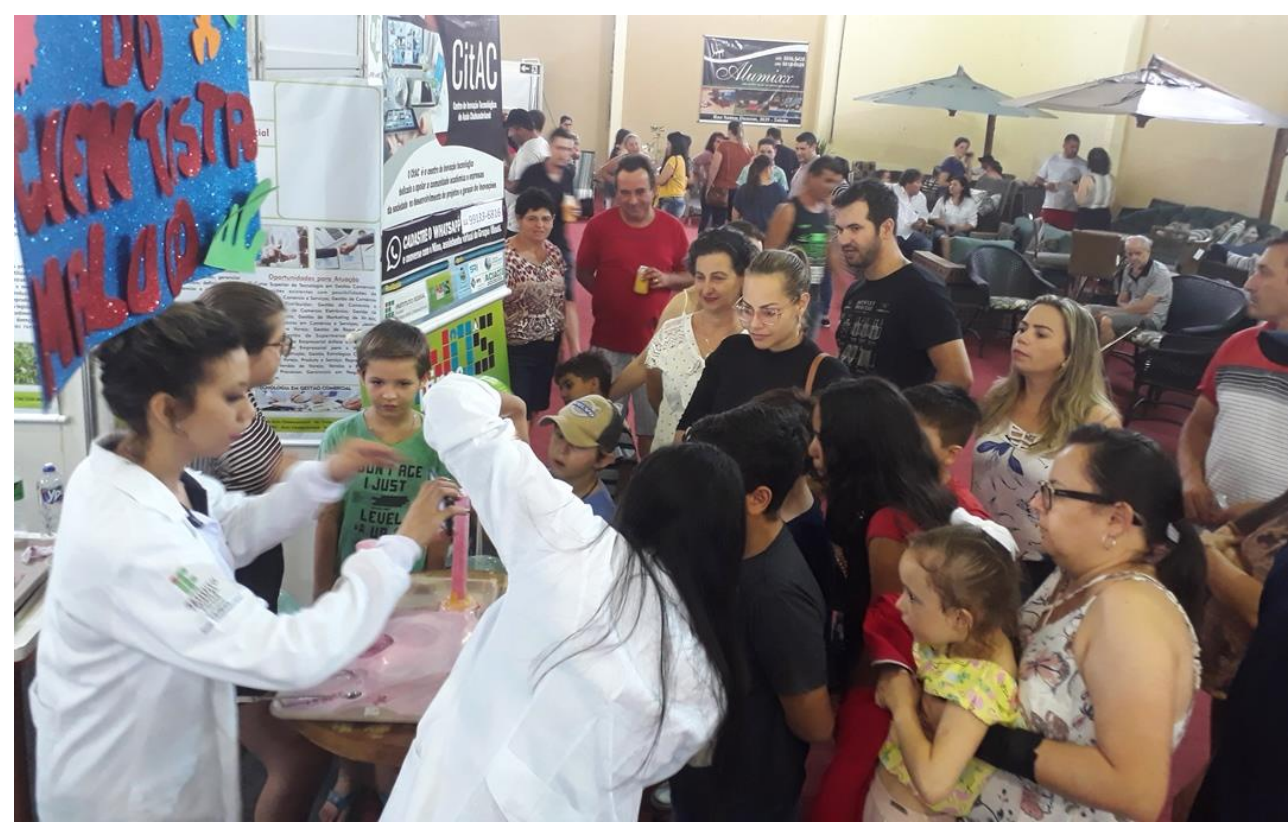

Figura 3. Apresentações de experiências na área de Biologia e Química para o público visitante da ExpoAssis, evento que acontece anualmente, em Assis Chateaubriand. Fontes: dos autores.

O impacto e a transformação social dos envolvidos, foram constatados em alguns depoimentos, descritos abaixo:

[...] sou estudante de licenciatura em ciências Biológicas no IFPR e eu amo estar envolvida com projetos relacionados principalmente à comunidade externa. E quando recebi o convite do projeto "interação total" fiquei muito feliz, pois foi uma honra poder fazer parte de muitas histórias e experiências envolvidas com pessoas para pessoas. Cada detalhe pensado, cada tema bem elaborado, me fizeram renascer e pensar que eu posso mudar um dia de uma pessoa, que eu posso pelo menos levantar sua autoestima, que posso sentar e ouvir suas histórias, e assim mudar a minha também. Mudou a minha história, meu jeito de pensar, pois quando eu entrei no IFPR eu estava totalmente perdida, o curso não era o que eu queria, e tinha perdido minha mãe com câncer em dois meses, meu mundo em si não era mais o mesmo, meus pensamentos, minha fé, minha relação com as pessoas era totalmente diferente. E no projeto eu pude renascer, eu pude conhecer pessoas, conhecer meus colegas de turma, eu pude me entender melhor. Aprendi muita coisa, e uma lição que tiro disso é que os seres humanos possuem problemas e até demais, porém é você quem decide se aprende com o problema a ser forte ou ele te derruba. Enfim eu me doei inteiramente ao projeto e tenho certeza que minhas amigas também, foi uma experiência incrível, fez entender que podemos ser estudantes e podemos ser melhores a cada instante como pessoa principalmente (comunicação pessoal) ${ }^{1}$.

Cada indivíduo tem suas particularidades que o diferem de outros. Por isso a forma e o prazer em aprender também são diversos. Para o mim o projeto interação total foi como um grande salto na formação acadêmica. Digo isso, por que sempre tive desejo de participar de trocas de experiências como graduanda do Instituto federal Campus Assis Chateaubriand e contribuir com a comunidade local. Seja ela levando um sorriso ou contribuindo com alguns conhecimentos. Acredito que a formação acadêmica para ser completa tem que haver desenvolvimento de ações que visam valorizar a formação de um cidadão consciente e humanizado. A contribuição do projeto foi além. Sou uma pessoa muito tímida, e o projeto me proporcionou novos horizontes, percebi o quão importante é saber se comunicar e se portar corretamente próximo às pessoas seja professores ou público em geral. Sabe se que para romper a insegurança e a timidez é necessário treino. E o projeto me proporcionou muitos momentos de interação com o público. Por tudo isso agradece muito ter tido a oportunidade de participar do projeto. Meu muito obrigada aos professores mentores deste projeto. Sou uma cidadã e aluna mais consciente dos meus deveres e valor após Projeto Interação total (comunicação pessoal)? 
Neste projeto tive a oportunidade de fazer novas amizades e poder interagir com a comunidade externa por meio de diversas oficinas que fizeram a diferença na vida das pessoas que estavam participando e também para mim, como estudante, por poder proporcionar as palestras e oficinas promovendo autoestima. Muitas mulheres que chegaram no espaço estavam desanimadas e saíram de lá felizes e contentes com um sorriso enorme no rosto (comunicação pessoal) ${ }^{3}$.

O projeto interação me proporcionou um nuance de experiências magnificantes, que acrescentou a mim e colegas como discentes e ser humano, oferecendo oportunidades de transformar e levar conhecimento à comunidade externa. O resultado foi renovador e gratificante a todos os envolvidos, só tenho a agradecer o espaço que foi franqueado a mim, todas as experiências foram de grande valia e as levarei para sempre na minha vida pessoal e acadêmica. Finalizo este depoimento com muita alegria e emoção e com um imensurável sentimento de gratidão (comunicação pessoal) ${ }^{4}$.

\section{Discussão}

De acordo com as experiências apresentadas, a extensão demonstra para a sociedade o compromisso social que as instituições de educação possuem, e também coloca em prática o conhecimento adquirido em sala de aula e para fora dela (Rodrigues, 2013). Neste contexto, o estudante é o protagonista deste processo, indo até a comunidade ou recebendo-a para promover a disseminação do conhecimento, a troca de saberes e o estreitamento de laços. A aquisição do conhecimento para os diversos gêneros gera oportunidades e melhorias das condições de vida pessoal e familiar. Fonseca (1995) cita o conceito de conhecimento, definido por Severino (1993, p. 210):

O esforço do "espírito" para compreender a realidade objetiva, dando-lhe um sentido, um significado, mediante o estabelecimento de nexos aptos a satisfazerem as exigências intrínsecas de sua subjetividade. Mas são várias as formas de conhecimento, culturalmente já caracterizadas, em função das peculiaridades de seu processo de elaboração: assim, o senso comum, o mito, a religião, a arte, a ciência são, de suas perspectivas específicas, esforços de compreensão dos vários aspectos do real.

A educação muda pensamentos, eleva a autoestima, gera um ser pensante e racional, ou seja, transforma vidas e diversas atividades podem oportunizar mudanças de paradigmas (Barbosa, 2004). Nesta linha de pensamento, uma das oficinas teve como foco a valorização do trabalho feminino e a união entre as mulheres para criarem mecanismos de sobrevivência, frente a diversas adversidades que a vida lhes impõe. Assim, quando a mulher visualiza e sente que está colaborando, como, por exemplo, financeiramente para o sustento de sua família e inserida socialmente, passa a perceber o quanto é capaz e como pode modificar as situações de dificuldades que enfrenta. Isso leva ao afloramento de ações, delineadas e executadas devido à motivação e força de vontade, alcançando resultados positivos, proporcionando, assim, um crescimento e mudanças de paradigmas (Perdun et al., 2009). Produzir e comercializar os próprios produtos demonstram a capacidade e a força que as mulheres possuem para transformar vidas em uma sociedade moderna, utilizando a arte da vontade e da perseverança.

As ações "O cientista maluco" e o teatro "O chá da vovó" foram planejadas para crianças, uma vez que, enquanto futuros educadores, os acadêmicos e acadêmicas envolvidos sabem que o meio é a condição para qualquer aspecto fisiológico e neurológico, estimulando a intelectualidade. Assim, a criança "copia modelos, e os vivencia a seu modo, ou seja, para o mundo adulto, dessa forma, se prepara gradativamente para o futuro, experimentando a realidade de seu meio" (Trettel \& Batista, 2016). Quando estimulamos e proporcionamos à criança atividades de sentir, pensar e fazer, o lúdico estreita os laços entre o ser e o aprendizado (Gonçalves, 2018). Embasado nisso, o autodesenvolvimento pode ser estabelecido e aguçado utilizando a 'brincadeira' como uma valiosa ferramenta (Silber, 2019). A alegria e felicidade ficam estampadas nos rostinhos de qualquer criança, independente da classe social a que elas pertencem, quando trabalhos lúdicos são realizados. As 
atividades de extensão com temas científicos, trabalhados de forma lúdica, promovem o estabelecimento de parceria entre o espaço escolar e a família de crianças. A participação da família no cotidiano escolar é fundamental, porque também cabe à família a transmissão de valores morais, éticos e crenças que marcam a sociedade (Crepaldi, 2017).

Alunos da Associação de Pais e Amigos dos Excepcionais (APAE) também foram contemplados neste trabalho por meio do teatro. A interação com esse público durante a apresentação do teatro foi extremamente enriquecedora. Foi possível observar a ansiedade que eles tinham em participar, contando que suas avós e mães faziam o chazinho com as plantinhas. A Lei de Diretrizes e Bases da Educação Nacional - LDB (Lei n. 9394/96) preconiza "igualdade de condições para o acesso e permanência na escola", para todos. Os trabalhos de extensão sempre abrem portas para diversos públicos, principalmente quando é considerada a inclusão. Assim, as atividades de extensão ligadas ao ensino e pesquisa podem promover no educando com deficiências múltiplas a convivência com pessoas sem necessidades especiais, e com isso potencializar o aprendizado de todos, "pois concebe a relação com o outro como peça fundamental do processo de apropriação do conhecimento" (Vieira et al., 2018).

Questões relevantes sobre a área de Educação Ambiental (EA), abordando o cuidado com os ecossistemas e a biodiversidade, foram tratadas na oficina de recuperação de nascentes. Nesta oficina, estudantes do curso de Licenciatura em Ciências Biológicas puderam aplicar conhecimentos na prática, e tiveram a oportunidade de recuperar uma nascente em zona rural. A união entre a teoria e a prática utilizando o ambiente natural sensibiliza e conscientiza sobre a valoração da biodiversidade, e resulta tanto na ampliação do conhecimento quanto no interesse pela conservação, ferramentas eficazes para o ensino da EA (Nunes et al., 2017) e também para o sucesso da ação extensão entre estudantes e comunidade rural.

Conforme citado por Lima (2003), as instituições de ensino necessitam estar inseridas ad eternum na comunidade, promovendo o intercâmbio de experiências, reajustando, sempre que necessário, valores e prioridades, permitindo, assim, que a população seja protagonista de sua própria história, podendo atuar na resolução de problemas dentro de sua própria comunidade.

\section{Considerações finais}

O prazer, a satisfação, o gosto, a sensação de fazer a diferença e o entusiasmo em desenvolver ações de extensão estabelecem de forma sólida e duradoura os laços entre a instituição de ensino e a comunidade externa, tendo os estudantes sendo atores principais. Inclui-se nessa comunidade um público geralmente sem poder de fala. As estudantes voluntárias do curso de Licenciatura em Ciências Biológicas, estimuladas e orientadas ao desenvolvimento de sua criatividade e à liberdade na difusão dos conhecimentos construídos, apresentaram a capacidade de atuarem como agentes transformadores, consagrando o significado da extensão acadêmica.

\section{Agradecimentos}

Os autores agradecem ao campus Assis Chateaubriand do IFPR, a prefeitura Municipal de Assis Chateaubriand (setor de Secretaria de Agricultura, Meio Ambiente, Serviços Urbanos e Obras - representante Juliana Correia e a Unidade de Valorização de Materiais Recicláveis e Coordenadora Pedagógica na Secretaria de Educação representante Cássia Tamparowsky); a ITAIPU BINACIONAL (Programa Encontros e Caminhos) pelo apoio financeiro, logístico e pessoal. E a todos que contribuíram de forma direta e indireta para realização deste. 


\section{Contribuição de cada autor}

Os autores A.L.S.L. e F.Z. planejaram o projeto, atuaram como coordenadores, executores e escreveram o texto para o artigo. G.M.G., C.M.S.P., S.B.R.A., J.A.S.N. e D.J.C.S planejaram o projeto e foram as estudantes voluntárias que atuaram ativamente na execução do trabalho.

\section{Notas}

$1 \mathrm{E}$-mail recebido pela estudante do curso de Licenciatura em Ciências Biológicas S.B.R.A, acadêmica voluntária do presente projeto, Assis Chateaubriand, PR, em 29 de novembro de 2019.

2 E-mail recebido pela estudante do curso de Licenciatura em Ciências Biológicas G. M. G., acadêmica voluntária do presente projeto, Assis Chateaubriand, PR, em 29 de novembro de 2019.

3 E-mail recebido pela estudante do curso de Licenciatura em Ciências Biológicas C. M. S. P., acadêmica voluntária do presente projeto, Assis Chateaubriand, PR, em 03 de dezembro de 2019.

4 E-mail recebido pela estudante do curso de Licenciatura em Ciências Biológicas J. A. S. N., acadêmica voluntária do presente projeto, Assis Chateaubriand, PR, em 04 de dezembro de 2019.

\section{Referências}

Barbosa, M. S. S. (2004). O papel da escola: Obstáculos e desafios para uma educação transformadora (Dissertação de Mestrado). Universidade Federal do Rio Grande do Sul, Porto Alegre, Brasil. Recuperado de https://www.lume.ufrgs.br/ bitstream/handle/10183/6668/000488093.pdf?sequence $=1$

Crepaldi, E. M. F. (2017). A importância da família na escola para a construção do desenvolvimento do aluno. Anais do XIII Congresso Nacional de Educação, Curitiba - PR. Recuperado de https://educere.bruc.com.br/ arquivo/pdf2017/25972 13983.pdf

Fonseca, R. M. G. S. da. (1995). A educação e o processo de inclusão - exclusão social da mulher: uma questão de gênero? Revista Brasileira de Enfermagem, 48(1), 51-59.

Gonçalves, L. J., \& Costa, C. R. B. (2018). O brincar na Educação Infantil como um ato de aprendizagem. Revista Científica Multidisciplinar Núcleo do Conhecimento, 1(2), 175-186.

Lima, C. L. D. C. (2003). O papel da extensão na universidade. Leopoldianum, 28(78), 11-38.

Nonaka, L. (2017). A escola e sua responsabilidade social. Recuperado de https://educacao.estadao.com.br/ blogs/colegio-prudente/a-escola-e-sua-responsabilidade-social/

Nunes, M. E. R., França, L. F., \& Paiva, L. V. (2017). Eficácia de diferentes estratégias no ensino de educação ambiental: associação entre pesquisa e extensão universitária. Ambiente e Sociedade, 20(2), 59-76.

Perdun, F., Silva, D. A. K., \& Baldin, N. (2009). Inclusão social das mulheres - catadoras: atividade reciclável artesanal como forma de valorização do ser humano e seu potencial. Anais do IX Congresso Nacional de Educação e III Encontro Sul Brasileiro de Psicopedagogia, Curitiba. Paraná: PUC. Recuperado de https://educere.bruc.com.br/arquivo/ pdf2009/2545 1087.pdf

Rodrigues, A. L. L.; Prata, M. S. P.; Batalha, T. B. S., Costa, C. L. N. A. \& Passos Neto, I. F. (2013). Contribuições da Extensão Universitária na sociedade. Cadernos de Graduação - Ciências Humanas e Sociais, 1(16), 141-148.

Severino, A. J. (1993). Filosofia. São Paulo: Cortez.

Silber, C. H. (2019). O lúdico como facilitador do processo de aprendizagem na educação infantil. Revista Científica Multidisciplinar Núcleo do Conhecimento, 1, 85-96. 
Trettel, U. R. \& Batista, E. C. (2016). A importância da brincadeira no processo de ensino e aprendizagem na educação infantil. Extensio: Revista Eletrônica de Extensão, 4 (1), 18-31.

Velloso, M. P. (2005). Os catadores de lixo e o processo de emancipação social. Ciência \& Saúde Coletiva, 10, 49-61.

Vieira, A. B., Ramos, I. O., \& Simões, R. D. (2018). Inclusão de alunos com deficiência e transtornos globais do desenvolvimento: atravessamentos nos currículos escolares. Educação e Pesquisa, 44, 1-18.

Zucco, F. D., de Quadros, C. M. B., \& Bona, R. J. (2019). Extensão universitária no curso de publicidade e propaganda: Perspectivas acadêmicas e comunitárias do projeto comunicação para o desenvolvimento social. Extensio: Revista Eletrônica de Extensão, 16(34), 19-33.

Como citar este artigo:

Lima, A. L. da S., Zanella, F., Gimenes, G. M., Pin, C. M. da S., Albuquerque, S. B. R., Nascimento, J. A. de S., \& Santos, D. J.P. C. (2021). Educação Ambiental nos anos iniciais do ensino fundamental: Várias formas de trabalhar os seus temas. Revista Brasileira de Extensão Universitária, 12(1), 77-87. https://periodicos.uffs.edu.br/index.php/ $\underline{\text { RBEU/article/view/11460/pdf }}$ 